\section{Benefits of primary care}

SIR - In an article "Primary care is not the answer" (Nature 370, 501; 1994), Barbara J. Culliton draws attention to some "less visible provisions" in President Bill Clinton's health-care plan, such as forcing 50 per cent of physicians into general practice. She believes that this " 50 per cent solution" will fail, as modern medical practice is beyond the skills of the general practitioner. Medicine should be provided mainly by academic medical centres.

Primary care has always been the preferred way to practise medicine. Unfortunately, it has been abandoned by academic medicine. Diseases do not exist as such, there are only sick people, and yet our education systems produce mainly disease specialists. They may understand "basic biological phenomena", and know how to treat some diseases, yet the crucial question is not only how to treat but when to intervene. The latter is generally ignored because withholding treatment is regarded as unethical, and many patients therefore receive unnecessary treatment. Academic medicine turned primum non nocere into malpractice, and palliation into nonscience. And yet most patients do not need more than that, seeking help from alternative medicine.

An important objective of Clinton's plan is to mobilize competent "academic generalists" and place them where they are needed most, in the community. To restore the lost dignity of the family physician who now faces new responsibilities, and to protect his patient from academic medicine. Medicine has become extremely complex and the family physician has to decide what is best for his patient in the same way as a lawyer does for his client.

The threat of academic medicine to the patient is real. The family physician has to protect him from unnecessary treatment, experimental remedies and clinical trials that study disease and ignore patient suffering.

Academic medicine is the main source of iatrogenesis, that is, drug sensitivity and antibiotic resistance (hospital strain). It is also the main cause of rising medicalcare expenditure, as it indiscriminately applies technological innovations, when in reality the patient could benefit without them. As patient protector, the family physician will obviously also reduce medical expenses.

\section{Gershon Zajicek}

H. H. Humphrey Center for Experimental

Medicine and Cancer Research,

Hebrew University,

Hadassah Medical School,

PO Box 12272

Jerusalem 91120 ,

Israel
SIR - In her diatribe against the role of primary care in Clinton's plans for healthcare reform, Culliton demonstrates that C. Everett Koop does not have a monopoly on patent and dangerous nonsense. She misses the main point about general practice: namely that well-trained generalists act as vital gatekeepers for access to the specialists who are thereby allowed more time to practise their medicine on appropriate patients.

To take up her argument on "Koop's elbow", what if the pain is due to angina? Is the patient expected to know that in this instance a cardiologist would be better than a rheumatologist? Immediate access to specialist care in these circumstances is at best a waste of time and at worst dangerous, as life-saving treatment may be unnecessarily delayed. The United Kingdom's National Health care system may have many flaws, but, in the opinion of many doctors who work in it, a well organized network of highly trained general practitioners is not one of them. The United States would be well advised to emulate it.

\section{Cella Helliwell}

Andrew Hall

8 Park Avenue

Hexham, Northumberland NE46 3EN, UK

SIR - It was disappointing to see Nature dismiss efforts to reform the US healthcare system (Nature 369, 508; 1994). As a molecular biologist whose livelihood depends partly on continued government spending for basic medical research, I share your concern that this source of revenue should not be lost.

However, as a parent unable to purchase medical insurance to meet the cost of treating a haemophiliac child, I am aware of severe shortcomings in our health-care system. A single dose of clotting factor now retails for $\$ 1,300$. Our health-care dollars support large numbers of workers in the insurance, legal, administrative, pharmaceutical, marketing and other professions.

In a widely quoted recent statement, the former US Surgeon General, C. E. Koop, points out that 72 per cent of Britain's physicians are primary care doctors, compared to 29 per cent in the United States. It seems unlikely that free market forces will ever reverse these trends. Unless elected officials play an active, positive role in restructuring the US health-care system, the United States will probably never achieve what other developed countries have, in being able to provide basic medical security for working citizens and their families.

Mariana M. Goldrick

513 Pigeon Forge Road,

Pflugerville, Texas 78660, USA
Record conditions for cycling

SIR - Miguel Indurain recently broke the world 1-hour cycling record, riding 53.040 $\mathrm{km}$. The previous record was held by Graeme Obree, who rode an innovative bicycle of his own design and manufacture. Subsequently, the UCI (Union Cycliste Internationale) changed its rules to outlaw such innovations. The UCI does not, however, regulate the atmospheric pressure or composition used for the record attempt. That is why both the Merckx (1972) and Moser (1984) hour records were achieved at altitude in Mexico City, where the air is less dense than at other tracks. Indeed, both Obree and Indurain have plans to attack the record in Mexico City next year.

One of us recently proposed attempting the hour record in a depressurized indoor track filled with $\sim 0.2$ atm of pure oxygen ${ }^{1}$. This approximates to the atmosphere used in modern spacecraft, and has the same volumetric oxygen content as air. At world record speeds, frictional losses from tyres and drive train become an insignificant fraction of total resistance ${ }^{2}$

We can also assume that the drag coefficient will not change, a good assumption for bluff bodies at high Reynolds numbers ${ }^{3}$. For constant power output, the speed will then scale as density ${ }^{(-1 / 3)}$. For a 0.2 atm $\mathrm{O}_{2}$ atmosphere, the speed increases by a factor of $(0.2 \times 32 / 29)^{(-1 / 3)}=$ 1.655. The $32 / 29$ factor accounts for the higher molecular weight of $\mathrm{O}_{2}$ versus the average air molecule.

Almost any competitive cyclist could then break the current record (including either one of us) within the current UCI rules. Obree or Indurain could ride more than $87 \mathrm{~km}$ in one hour to take the title definitively.

The hour cycling trial is one of the most difficult of all sporting events, and those currently contesting it are arguably the fittest of all humans. Thus the proposed experiment would test the absolute limits of human physical performance under space flight conditions.

Jonathan E. Snow

CNRS/CRPG,

BP20,

54501 Vandoeuvre-les-Nancy, France

Mark Drela

Department of Aeronautics

and Astronautics,

Massachussetts Institute of Technology,

Cambridge, Massachusetts 02139, USA

\footnotetext{
1. Snow, J. \& Shames, P. UK Cycling Weekly, No. 5332, p. 27 (1994).

2. Whitt, F. \&Wilson, D. G. Bicycling Science (MIT Press, Cambridge, 1983).

3. Hoerner, S Fluid Dynamic Drag (Hoerner Fluid Dynamics, 1967).
} 